\title{
Pengaruh Gaya Kepemimpinan Terhadap Motivasi Kerja Pegawai Pada Badan Pengelola Usaha Universitas Lampung Di Bandar Lampung
}

\author{
Maria Elina $^{1 *}$, Sodirin $^{1}$, Ida Royati $^{1}$ \\ ${ }^{1}$ Universitas Sang Bumi Ruwa Jurai \\ ${ }^{*}$ Correspondence : maria.elina@fe.saburai.ac.id
}

\begin{abstract}
Abstrak.
Penelitian ini bertujuan untuk mengetahui apakah terdapat pengaruh gaya kepemimpinan terhadap motivasi kerja. Penelitian ini menggunakan tekhnik pengumpulan data field research (penelitian lapangan ). Analisis data pada penelitian ini menggunakan uji normalitas dengan menggunakan metode Kolmogorov-smirnov dan regresi linear sederhana dengan perhitungannya berbantuan program SPSS. Hasil penelitian dan pembahasan diperoleh nilai signifikansi sebesar 0,000 lebih kecil dari taraf signifikansi 0,05 . Kemudian nilai thitung $(5,399)$ $>t_{\text {tabel }}(2,048)$. Hal ini menunjukkan bahwa terdapat pengaruh gaya kepemimpinan terhadap motivasi kerja pegawai pada Badan Pengelola Usaha (BPU) Universitas Lampung atau dengan kata lain $\boldsymbol{H}_{\boldsymbol{a}}$ diterima. Persentase pengaruh gaya kepemimpinan terhadap motivasi kerja sebesar $51 \%$.
\end{abstract}

Kata kunci: Badan Pengelola Usaha, Gaya Kepemimpinan, Motivasi Kerja

\section{Abstract.}

This study aims to determine whether there is an influence of leadership style on work motivation. This study uses field research data collection techniques (field research). Data analysis in this study used the normality test using the Kolmogorov-Smirnov method and simple linear regression with the calculation assisted by the SPSS program. The results of the research and discussion obtained a significance value of 0.000 which is smaller than the 0.05 significance level. Then the value of thitung $(5,399)>t_{\text {tabel }}(2,048)$. This shows that there is an influence of leadership style on employee work motivation at the University of Lampung Business Management Agency (BPU) or in other words $\boldsymbol{H}_{\boldsymbol{a}}$ is accepted. The percentage of the influence of leadership style on work motivation is $51 \%$.

Keywords: Business Management Agency, Leadership Style, Work Motivation

\section{PENDAHULUAN}

Pemimpin harus memahami betul siapa dirinya dan siapa yang akan dia pimpin (Sari, 2018) . Pemimpin merupakan individu yang bertanggungjawab terhadap segala sesuatu dalam mencapai tujuan dan prioritas dalam organisasi. Setiap pemimpin memiliki watak, sifat, dan karakter masing-masing yang dipengaruhi oleh faktor sifat sejak lahir maupun pembentukan dari lingkungan tempat dimana pemimpin tumbuh dan berkembang (Chaniago, 2017). Pemimpin merupakan salah satu elemen dasar dari kepemimpinan (Boiliu, 2021).
Kepemimpinan merupakan perilaku pemimpin yang digunakan seseorang ketika ingin mempengaruhi orang lain (Khairizah, Noor, \& Suprapto, 2016). Gaya kepemimpinan diukur dengan pengambilan keputusan, orientasi pemimpin serta keputusan pemimpin (Aisyah \& Wardani, 2020). Gaya kepemimpinan mampu digunakan oleh seorang pemimpin untuk memotivasi bawahannya agar kinerja bawahannya dalam melakukan pekerjaan meningkat. Oleh karena itu, seorang pemimpin harus memiliki kapasitas utnuk membaca situasi yang dihadapi dan menyesuaikan gaya kepemimpinannya 
sesuai dengan situasi dan kondisi (Rosalina \& Wati, 2020).

Badan Pengelola Usaha (BPU) Universitas Lampung merupakan salah satu unit kerja pada Universitas Lampung yang mengelola gedung serba guna, kolam renang, rusunawa, wisma, kantin, dan food court yang menyumbang penerimaan negara bukan pajak (PNPB) di Universitas Lampung. Berikut data jumlah pegawai pada BPU Universitas Lampung:

Tabel 1. Data Pegawai Pada Badan Pengelola Usaha Universitas Lampung Tahun 2016 - 2020

\begin{tabular}{cc}
\hline Tahun & Jumlah Pegawai (Orang) \\
\hline 2016 & 34 \\
2017 & 34 \\
2018 & 34 \\
2019 & 34 \\
2020 & 30 \\
\hline
\end{tabular}

Berdasarkan tabel diatas dapat diketahui bahwa semenjak tahun 2016 hingga 2020 terdapat penurunan jumlah pegawai sebanyak 4 orang, hingga jumlah pegawai pada tahun 2020 menjadi 30 orang.

Badan Pengelola Usaha Unila menerapkan gaya kepemimpinan instruksi yaitu gaya kepemimpinan yang menitikberatkan kepada peran pemimpin dalam memberi batasan peran karyawan dan mengkomando tentang tugas, cara melakukan tugas tersebut serta dimana mereka harus mengerjakannya (Handojo, $\mathrm{Al}$ Juhani, Apiani, \& Johan, 2021). Penerapan gaya kepemimpinan ini menyebabkan kurangnya komunikasi yang harmonis serta kurangnya pembinaan kepada para karyawan yang menyebabkan tingkat kinerja pegawai menjadi rendah. Hal ini juga berdampak pada motivasi karyawan yang akibatnya adalah malas-malasan dalam bekerja. Oleh karena itu, seorang pemimpin harusnya mampu memberikan motivasi terhadap pegawainya untuk menciptakan produktivitas sehingga pekerja mampu mengeluarkan secara maksimal kinerjanya.

Seorang pemimpin dikategorikan sukses atau tidaknya apabila mampu memanfaatkan kemampuan yang dimilikinya untuk menggerakkan individu lain untuk mencapai tujuan dari organisasi tersebut. Oleh karena itu, kepemimpinan memiliki peranan penting dalam memotivasi karyawan agar mencapai tujuan secara keseluruhan.

\section{METODE PENELITIAN}

Metode penelitian yang digunakan dalam penelitian ini adalah metode penelitian asosiatif, atau penelitian berdasarkan hubungan yang bertujuan untuk mengetahui hubungan antar dua variable atau lebih yang mempunyai hubungan kausal (sebab-akibat) (Yohanson, Hakim, \& Alimuddin, 2021). Objek pada penelitian ini adalah gaya kepemimpin dan motivasi kerja pegawai. Lokasi penelitian adalah Badan Pengelolaan Usaha (BPU) Universitas Lampung dan pelaksanaannya terjadi pada bulan April-Juni 2021.

Tekhnik pengumpulan data yg digunakan pada penelitian ini adalah menggunakan tekhnik field research (penelitian lapangan) dengan menggunakan observasi, angket (kuisioner), wawancara, dan dokumentasi (Aeni \& Arifin, 2021). Analisis deskriptif digunakan untuk menganalisis data dengan cara mendeskripsikan data yang sudah terkumpul tanpa membuat kesimpulan yang bersifat generalisasi. Penelitian ini menggunakan analisis deskriptif untuk menghitung tanggapan atau capaian indikator (Takandjanjdi, 2015, p. 46) dengan rumus:

$$
\mathrm{CI}=\frac{\mathrm{JR}}{\mathrm{SI}} \times 100 \%
$$

Dimana:

CI : Capaian indikator

JR : Jumlah Jawaban Responden

SI : Skor Ideal (skor tertinggi dikalikan

jumlah responden)

Berikut ini merupakan kriteria capaian indikator (CI) sebagai berikut: 
Tabel 2. Kriteria Pengklasifikasian Presentase Skor Tanggapan Responden

\begin{tabular}{cc}
\hline Interval Skor & Kategori \\
\hline $0 \%-20 \%$ & Sangat Buruk \\
$21 \%-40 \%$ & Buruk \\
$41 \%-60 \%$ & Cukup \\
$61 \%-80 \%$ & Baik \\
$81 \%-100 \%$ & Sangat Baik \\
\hline Sumber: Riduwan (dalam Takandjanjdi, 2015:47)
\end{tabular}

Sebelum kuisioner digunakan perlu dilakukan uji validitas dan uji reabilitas. Pada penelitian ini uji regresi linier sederhana digunakan untuk mengetahui ada atau tidaknya pengaruh yang signifikan antara variabel bebas dengan variabel terikat. Rumus persamaan regresi linier sebagai berikut(Muhartini, Sahroni, Rahmawati, Febrianti, \& Mahuda, 2021):

dimana:

$$
Y=a+b X
$$

Y : Variabel terikat

A : Konstanta regresi

bX : Nilai turunan atau peningkatan variabel bebas

Sebelum dilakukannya uji regresi linier sederhana, terlebih dahulu dilakukan uji normalitas yang tujuannya untuk mengetahui apakah nilai residual berdistribusi normal atau tidak. Kemudian dilakukan uji linearitas yang tujuannya untuk mengetahui hubungan antara variabel bebas dengan variabel terikat.

Uji regresi linier sederhana dilakukan menggunakan program SPSS dan pengambilan keputusan dilakukan melalui dua cara yaitu:

- Membandingkan antara nilai sig. dan taraf signifikan $(0,05)$. Jika nilai sig. < 0,05 maka variabel $(\mathrm{X})$ berpengaruh terhadap variabel (Y) dan jika nilai sig. $>0,05$ maka variabel (X) tidak berpengaruh terhadap variabel (Y).

- Membandingkan antara nilai thitung dan $t_{\text {tabel }(a / 2 ; n-k-1)}$. Jika nilai $t_{\text {hitung }}>t_{\text {tabel }}$ maka variabel (X) berpengaruh terhadap variabel $(\mathrm{Y})$ dan jika nilai $\mathrm{t}_{\text {hitung }}<\mathrm{t}_{\text {tabel }}$ maka variabel $(\mathrm{X})$ tidak berpengaruh terhadap variabel (Y).

\section{HASIL DAN PEMBAHASAN}

Penelitian ini dilakukan untuk menganalisis gaya kepemimpinan pada Badan Pengelola Usaha Universitas Lampung terhadap motivasi kerja pegawai. Data yang diperoleh didapat melalui pemberian angket (kuesioner) yang diberikan kepada para pegawai Badan Pengelola Usaha Universitas Lampung. Angket yang digunakan berdasarkan kepada indikator gaya kepemimpinan yang telah disesuaikan melalui karakteristik gaya kepemimpinan yang diterapkan BPU Universitas Lampung yaitu gaya kepemimpinan instruksi.

Analisis data dalam penelitian ini dilakukan dengan beberapa tahap pengujian antara lain uji normalitas dengan menggunakan metode Kolmogorov-smirnov tes melalui program SPSS, serta dilakukannya uji regresi linier sederhana. Hasil analisis uji yang telah dilakukan dengan beberapa tahapan pengujian mendapatkan hasil sebagai berikut:

Tabel 3. Hasil Uji Normalitas Gaya Kepemimpinan Terhadap Motivasi Kerja

\begin{tabular}{llr}
\hline \multicolumn{2}{c}{ One-Sample Kolmogorov-Smirnov Test } \\
\hline & & $\begin{array}{c}\text { Unstandardized } \\
\text { Residual }\end{array}$ \\
\hline $\mathrm{N}$ & Mean & 30 \\
Normal & .0000000 \\
Parameters ${ }^{\mathrm{a} b}$ & Std. Deviation & 2.42954218 \\
Most Extreme & Absolute & .123 \\
Differences & Positive & .106 \\
& $\quad$ Negative & -.123 \\
Test Statistic & & .123 \\
Asymp. Sig. (2-tailed) & $.200^{\mathrm{c}, \mathrm{d}}$ \\
\hline a. Test distribution is Normal. & \\
b. Calculated from data. & \\
c. Lilliefors Significance Correction. \\
d. This is a lower bound of the true significance.
\end{tabular}

Berdasarkan tabel 3 diketahui hasil output dari One-Sample KolmogorovSmirnov Test diperoleh nilai sig. sebesar 0,200 . Nilai signifikansi yang diperoleh lebih besar dari taraf signifikansi 0,05. Hal 
ini menunjukkan bahwa nilai residual dari gaya kepemimpinan dan motivasi kerja berdistribusi normal.

Setelah data berdistribusi normal, maka selanjutnya dilakukan uji linearitas yang tujuannya untuk mengetahui bentuk hubungan gaya kepemimpinan terhadap motivasi kerja. Berikut tabel hasil uji linearitas gaya kepemimpinan terhadap motivasi kerja sebagai berikut:

Tabel 4. Hasil Uji Linearitas Gaya Kepemimpinan Terhadap Motivasi Kerja

\begin{tabular}{|c|c|c|c|c|c|c|c|}
\hline \multicolumn{8}{|c|}{ ANOVA Table } \\
\hline & & & $\begin{array}{c}\text { Sum of } \\
\text { Squares }\end{array}$ & Df & $\begin{array}{c}\text { Mean } \\
\text { Square }\end{array}$ & $\mathbf{F}$ & Sig. \\
\hline Motivasi_Kerja * & Between & (Combined) & 246.456 & 7 & 35.208 & 7.527 & .000 \\
\hline \multirow[t]{5}{*}{ Gaya_Kepemimpinan } & Groups & Linearity & 178.189 & 1 & 178.189 & 38.093 & .000 \\
\hline & & Deviation from & 68.267 & 6 & 11.378 & 2.432 & .059 \\
\hline & & Linearity & & & & & \\
\hline & Within Groups & & 102.910 & 22 & 4.678 & & \\
\hline & Total & & 349.367 & 29 & & & \\
\hline
\end{tabular}

Tabel 4 menunjukkan nilai sig. Deviation from Linearity pada ANOVA Table diperoleh sebesar 0,059 lebih besar dari taraf signifikansi 0,05. Maka dapat disimpulkan bahwa terdapat hubungan yang linear antara gaya kepemimpinan dan motivasi kerja.
Setelah mengetahui bahwa terdapat hubungan antara gaya kepemimpinan terhadap motivasi kerja maka selanjutnya melakukan uji regresi linear sederhana menggunakan program SPSS. Berikut tabel hasil uji regresi linear sederhana sebagai berikut:

Tabel 5. Hasil Uji Regresi Linear Sederhana Gaya Kepemimpinan Terhadap Motivasi Kerja

\begin{tabular}{|c|c|c|c|c|c|c|}
\hline \multicolumn{7}{|c|}{ Coefficients $^{\mathrm{a}}$} \\
\hline \multirow{2}{*}{\multicolumn{2}{|c|}{ Model }} & \multicolumn{2}{|c|}{ Unstandardized Coefficients } & \multirow{2}{*}{$\begin{array}{c}\begin{array}{c}\text { Standardized } \\
\text { Coefficients }\end{array} \\
\text { Beta }\end{array}$} & \multirow[b]{2}{*}{$\mathbf{T}$} & \multirow[b]{2}{*}{ Sig. } \\
\hline & & B & Std. Error & & & \\
\hline 1 & (Constant) & 7.190 & 2.458 & & 2.925 & .007 \\
\hline & Gaya_Kepemimpinan & .761 & .141 & .714 & 5.399 & .000 \\
\hline
\end{tabular}

Berdasarkan tabel 5 diatas dapat disimpulkan bahwa:

- Pada kolom Unstandardized Coefficients diperoleh nilai B untuk Constants sebesar 7,190 dan Gaya_Kepemimpinan sebesar 0,761, sehingga persamaan regresi linear dapat ditulis:

$$
Y=7,190+0,761 X
$$

Persamaan di atas dapat dijelaskan sebagai berikut:

- Konstanta sebesar 7,190 mangandung arti bahwa nilai konsisten variabel motivasi kerja sebesar 7,190.

- Koefisien regresi X sebesar 0,761 menyatakan bahwa setiap penambahan $1 \%$ nilai gaya kepemimpinan, maka nilai motivasi kerja bertambah sebesar 0,761. Kemudian regresi tersebut bernilai positif, sehingga dapat diketahui bahwa arah pengaruh gaya kepemimpinan terhadap motivasi kerja adalah positif.

- Berdasarkan nilai sig. pada Gaya_Kepemimpinan diperoleh sebesar 0,000 lebih kecil dari taraf signifikansi 0,05 . Kemudian nilai tabel untuk responden sebanyak 30 orang diperoleh sebesar 2,048 sehingga diketahui nilai $t_{\text {hitung }}(5,399)>t_{\text {tabel }}(2,048)$. Hal ini menunjukkan bahwa terdapat pengaruh gaya kepemimpinan terhadap motivasi kerja pegawai pada Badan Pengelola 
Usaha (BPU) Universitas Lampung atau dengan kata lain $H_{a}$ diterima.

Kemudian, besar pengaruh gaya kepemimpinan terhadap motivasi kerja peggawai Badan Pengelola Usaha Universitas Lampung dapat dilihat melalui tabel berikut ini:

Tabel 6 Besar Pengaruh Gaya Kepemimpinan Terhadap Motivasi Kerja Model Summary

\begin{tabular}{lcccc}
\hline \multicolumn{4}{c}{ Model Summary } \\
\hline Model & $\mathbf{R}$ & $\begin{array}{c}\mathbf{R} \\
\text { Square }\end{array}$ & $\begin{array}{c}\text { Adjusted } \\
\text { R Square }\end{array}$ & $\begin{array}{c}\text { Std. } \\
\text { Error of } \\
\text { the } \\
\text { Estimate }\end{array}$ \\
\hline $\mathbf{1}$ & $.714^{\mathrm{a}}$ & .510 & .493 & 2.47255 \\
\hline a. Predictors: (Constant), Gaya_Kepemimpinan & \\
\hline
\end{tabular}

Tabel 6 menunjukkan bahwa bahwa hasil output pada Model Summary diperoleh nilai korelasi/hubungan (R) sebesar 0,714. Dari output tersebut diperoleh koefisien determinasi (R Square) sebesar 0,510 yang mengandung pengertian bahwa pengaruh gaya kepemimpinan terhadap motivasi kerja sebesar $51 \%$.

Berdasarkan hasil pengujian secara statistik diatas, dapat diketahui bahwa terdapat pengaruh antara variabel bebas dengan variabel terikat yaitu gaya kepemimpinan terhadap motivasi kerja. Hal ini selaras dengan penelitian yang dilakukan oleh Xaverius Sinuraya (2018, p. 98) yang menyatakan bahwa gaya kepemimpinan instruksi berpengaruh secara signifikan terhadap variabel motivasi kerja.

\section{KESIMPULAN}

Hasil penelitian yang dilakukan oleh peneliti memiliki kesimpulan yaitu Terdapat pengaruh gaya kepimpinan terhadap motivasi kerja karyawan Badan Pengelola Usaha (BPU) Universitas Lampung. Lingkungan kerja Badan Pengelola Usaha (BPU) Universitas Lampung membangkitkan minat pegawai terhadap suatu pekerjaan.

\section{DAFTAR PUSTAKA}

Aeni, N., \& Arifin. (2021). Pengaruh Kompetensi Dan Pengembangan Karier Terhadap Kinerja Pegawai Pada Dinas Perkebunan Kabupaten Way Kanan. 6, 113-120.

Aisyah, S. N., \& Wardani, R. (2020). Pengaruh Gaya Kepemimpinan Terhadap Kinerja Karyawan. 1(1), 42-50.

Boiliu, N. I. (2021). Pemimpin dan Perubahan. TE DEUM (Jurnal Teologi Dan Pengembangan Pelayanan), 3(2), 229-241. https://doi.org/10.51828/td.v3i2.98

Chaniago, A. (2017). Pemimpin dan kepemimpinan. Pemimpin Dan Kepemimpinan, 10(9).

Handojo, W., Al Juhani, A. A. S., Apiani, D. I. N., \& Johan, J. (2021). Analisis tipe gaya kepemimpinan yang berpengaruh terhadap kinerja karyawan PT Ayo Media Network. Jurnal Manajemen Maranatha, 20(2), 145-158. https://doi.org/10.28932/jmm.v20i2.3 041

Khairizah, A., Noor, I., \& Suprapto, A. (2016). Pengaruh gaya kepemimpinan terhadap kinerja karyawan (studi pada karyawan di Perpustakaan Universitas Brawijaya Malang). Jurnal Administrasi Publik (JAP).

Muhartini, A. A., Sahroni, O., Rahmawati, S. D., Febrianti, T., \& Mahuda, I. (2021). Analisis Peramalan Jumlah Penerimaan Mahasiswa Baru Dengan Menggunakan Metode Regresi Linear Sederhana. Jurnal Bayesian: Jurnal Ilmiah Statistika Dan Ekonometrika, 1(1).

Rosalina, M., \& Wati, L. N. (2020). Pengaruh Gaya Kepemimpinan Terhadap Disiplin Kerja Dan Dampaknya Terhadap Kinerja Karyawan. Jurnal Ekobis : Ekonomi Bisnis \& Manajemen, 10(1), 18-32. https://doi.org/10.37932/j.e.v10i1.26

Sari, I. S. J. (2018). Hakekat, Dinamika 
Organisasi , Dan Fungsi Pemimpin Dan Kepemimpinan Pendidikan Islam. 13, 26-37.

Sinuraya, X. (2018). Pengaruh Gaya Kepemimpinan Terhadap Motivasi Kerja Karyawan Pada Divisi Produksi PT. Gardenia Makmur Selaras. Universitas Katolik Parahyangan.

Takandjanjdi, O. (2015). Pengaruh Gaya
Kepemimpinan Terhadap Motivasi Kerja Pegawai. Universitas Terbuka Jakarta.

Yohanson, A. K., Hakim, L., \& Alimuddin. (2021). Motivasi Kerja Terhadap Kinerja Karyawan Pt . Japfa Comfeed Indonesia Tbk, Cabang Tanggamus. 06(September), 23-28. 